\title{
Multivessel Percutaneous Coronary Intervention in Patients with Acute ST-segment Elevation Myocardial Infarction in Same Sitting
}

\author{
AHM Waliul Islam, Shams Munwar, Azfar H. Bhuiyan, Sahabuddin Talukder, AQM Reza, \\ Tamzeed Ahmed, Nighat Islam, Atique bin Siddique, Intekhab Yousuf, Shaifur Rahman Shohel, \\ Sarder Md Tanvir, Aparajita Karim, Tanvir Ahmed, M S Alam \\ Dept. of Invasive and Interventional cardiology, Apollo Hospitals Dhaka
}

\begin{abstract}
:
Key Words : Background: Aim of the study was to evaluate the primary procedural success of Multivessel Acute MI, Multivessel PCI, Primary PCI, Infarct related artery. Percutaneous coronary intervention in patients with acute ST-segment elevated myocardial infarction at the same sitting.

Methods: Total $23(13.4 \%)$ patients were enrolled in this very preliminary study, among the total 171 patients who had primary PCI at our center from Jan 2010 to February 2015. Among them, Male: 20 and Female: 3. Total 52 stents were deployed in 46 territories. Mean age were for both male and female were 54 yrs. Associated coronary artery disease risk factors were Dyslipidemia, High Blood pressure, Diabetes Mellitus, positive family history for coronary artery disease and Smoking.

Results: Among the study group; 17(74\%) were Dyslipidemic, 11(47.8\%) were hypertensive; 8(34.8\%) patients were Diabetic, positive family history 4(17.4\%) and 9(39\%) were all male smoker. Female patients were more obese (BMI: M 26: F 27). Common diagnosis at admission based on ECG evidence was; Inferior wall myocardial infarction: 12 (52.2\%), Anterior wall myocardial infarction 9(39.1\%) and lateral 2(8.7\%). Common stented territory was left anterior descending artery 9(39.1\%), right coronary artery $7(30.4 \%)$, and left circumflex artery $7(30.4 \%)$. Stent used: Bare metal stent 3 (5.7\%), DES: 49 (94.2\%). Among the different drug eluting stents, Everolimus 26 (52\%), Sirolimus 8(15.4\%) and Zotarolimus 9(17.3\%), Paclitaxel 2 (3.8\%), Biolimus 2 (3.8\%), Genous 2 (3.8\%).

Conclusion: In the current prospective non randomized study, we found that the multivessel primary PCI for ST elevation myocardial infarction with non-culprit vessel are suitable for PCI at the same sitting with better in-hospital and 1 yr survival outcome.
\end{abstract}

(Cardiovasc. j. 2015; 8(1): 53-58)

\section{Introduction:}

The primary objectives of percutaneous coronary intervention (PCI) in patients with ST- segment elevation myocardial infarction (STEMI) are to restore epicardial flow and myocardial perfusion in the culprit vessel. However, pathophysiological process is not limited to the culprit vessel. ${ }^{1}$ It is estimated that $40 \%$ to $65 \%$ of the patients presenting with STEMI have multivessel disease (MVD), which has been associated with worse clinical outcomes as compared with single-vessel disease. ${ }^{2,3}$ Patients with MVD have in addition to the culprit lesion, 1 or more significant lesion in nonculprit vessel. STEMI patients with MVD are at higher risk of heart failure and Cardiogenic shock and associated with two times higher mortality during hospitalization and long term follow up. ${ }^{4}$ Although, ACC/AHA guideline for PCI in STEMI not to recommend PCI of non-culprit lesion during primary $\mathrm{PCI}(\mathrm{pPCI})$ of culprit lesion in patients without haemodynamic compromise (Class III, Level of Evidence: C). ${ }^{5,6}$ Many of the investigator showed that PCI of a non-infarct artery at the time of pPCI is associated with worse clinical

Address of Correspondence : Dr. A H M Waliul Islam, Dept of Interventional and Invasive Cardiology, Apollo Hospitals Dhaka, Bangladesh. E-mail: ahmwislam@apollodhaka.com 
outcomes. ${ }^{7-9}$ The recommended PCI strategies for STEMI patients with MVD were defined as follows: The Culprit vessel only PCI (Culprit PCI), strategy was defined as PCI confined to culprit vessel lesion only. ${ }^{3}$ The Multivessel Percutaneous coronary intervention (MV-PCI) strategy was defined as well as e" 1 nonculprit vessel lesion was treated. The staged PCI strategy was defined as PCI confined to culprit vessel lesions only, after which e" 1 lesions in nonculprit vessel were treated during planned secondary procedures. ${ }^{10}$ With the advent of technical improvement in the coronary intervention, evolution of noble drug eluting stent (DES), anti platelet therapy, intravascular imaging, FFR, active discussion regarding the safety of MVPCI have been under taken. We have carried out, this very preliminary non-randomized prospective cohort on pPCI in STEMI patients with multivessel coronary artery disease and followed up clinically at our cardiac outpatient department.

\section{Methods:}

\section{Study Population:}

From January 2010 to February 2015, total 171 patients with acute STEMI had pPCI, after getting written consent from patient as well as the first degree relative. Patient who refused pPCI were treated with Thrombolysis and excluded from the study. Among these 171 patients, only 23 (13.4\%) patients have MVD. Primary PCI of infarct related artery was done along with the non-culprit vessel in same sitting.

\section{Definitions and Coronary Angiography}

The diagnosis of acute myocardial infarction was based on clinical presentations, increased cardiac biomarkers Troponin-I and 12-lead electrocardiogram findings. Among these patients, the diagnosis of STEMI was made when their ECG shows acute ST elevation of at least $1 \mathrm{~mm}$ in two or more contiguous limb leads or $2 \mathrm{~mm}$ in precordial leads.

The pPCI was defined when it is performed in patients within $12 \mathrm{hrs}$ of onset of STEMI. The culprit artery was determined with ECG, Echocardiographic and angiographic findings by each operator.
The definition of infarct related artery (IRA) revascularization of only one culprit lesion in multivessel CAD during the index hospitalization. MVD was defined as a significant stenosis in $\geq 1$ major epicardial vessel or side branch. ${ }^{7,26}$ The definition of MV-PCI, is PCI of $\geq 2$ coronary vessel including culprit artery during the index hospitalization.

A successful PCI was documented by self reporting operator in our center and accepted when defined to achieve angiographic success without associated in-hospital major clinical outcomes such as death, MI, cerebrovascular event and emergency CABG.

Coronary angioplasty was performed according to standard rules. Thrombus suction and predilatation was optional before stent implantation with a shorter balloon to avoid geographic miss. A successful procedures was defined as TIMI-3 antegrade flow, and $<20 \%$ residual stenosis in two orthogonal views. Post-deployment dilation was performed at high inflation pressure in all patients.

In-hospital complications including in-hospital mortality were analyzed. Primary clinical endpoint is cumulative major adverse cardiac event (MACE), include all cause death, myocardial infarction, repeated revascularization, and repeat PCI and CABG. Re-PCI includes target lesion revascularization (TLR), target vessel revascularization (TVR) and non-culprit vessel revascularization. Secondary, endpoints are defined as mace and each component during 1month follow up, stent thrombosis during the 12 month follow-up and each component of MACE during the 12-month follow up.

\section{Drug Therapy}

All the patients received Aspirin $300 \mathrm{mg} /$ day and Clopidegrol as a loading dose $300 \mathrm{mg}$ prior to PCI and continued for 9-12 months and received atorovastatin along with standard medical management for CAD. During the procedure, an intravenous heparin bolus (100IU/Kg) and GP IIb/ IIIa receptor blocker Integrillin were administered as required. The use of GP IIb/IIIa Receptor blocker was recommended as per protocol. Quantitative angiographic measurements of the target lesion were obtained in order to deploy 
correct size stent. In the event of chest pain, postprocedural ECG was measured and compared with the baseline. Check angiogram were taken, whenever indicated.

\section{Stents:}

Among the stent used; BMS used were microDriver, DES: Resolute Integrity (Medtronic, USA), Cypher (Cordis, USA), Promus Element (Boston Scientific, USA) and Endeavor Resolute (Medtronic, USA, Xience Prime, Xience V, Xience Integrity (Abbott vascular), Biomatrix (Biosensor) and Bioengineered Genous stent(OrbusNeich).

Data: Data were presented as mean \pm SD with percentage. Significant culprit coronary artery lesion was defines as stenosis as greater than $70 \%$ narrowing in angiogram with ECG changes of infarct artery related territory and serum Troponin-I level and clinical symptoms.

\section{Results:}

Table I. Shows the profile of studied population. Female patients were more obese (BMI; M 26: F 27). CAD risk factors were more in male than female. Table II. Shows the average size of stent used. Fig 1. Shows the percentage distribution of CAD risk factors. Among the study group; 17(74\%) were Dyslipidemic, 11(47.8\%) were hypertensive; $8(34.8 \%)$ patients were Diabetic, FH 4(17.4\%) and 9(39\%) were all male smoker. Fig 2 . Shows the percentage distribution of common presentation of acute STEMI; Inferior wall MI was in 12 (52.2\%), Anterior wall MI was 9(39.1\%) and lateral was 2(8.7\%). Fig 3. Shows the percentage distribution of the pPCI territory; Left anterior descending artery (LAD) 9(39.1\%), Right coronary artery (RCA) 7(30.4\%), Left circumflex artery (LCX) 7(30.4\%).

Table-I

Demographic Profile of patient.

\begin{tabular}{lcc}
\hline & Male & Female \\
Number & 19 & 4 \\
\hline Age $(\mathrm{yrs})$ & $54.1 \pm 8.5$ & $54.3 \pm 9.1$ \\
$\mathrm{BMI}\left(\mathrm{kg} / \mathrm{m}^{2}\right)$ & $26.0 \pm 3.2$ & $27.0 \pm 4.7$ \\
$\mathrm{SBP}(\mathrm{mmHg})$ & $125.0 \pm 15.7$ & $130.0 \pm 10.0$ \\
$\mathrm{DBP}(\mathrm{mmHg})$ & $74.5 \pm 5.2$ & $80 \pm 10$ \\
No. Risk Factor & $2.4 \pm 0.6$ & $2.3 \pm 0.6$ \\
Creatinine mmol/L & $1.3 \pm 0.3$ & $1.04 \pm 0.3$ \\
\hline
\end{tabular}

Data were presented as Mean \pm SD.

\section{Table II}

Average size of Stent used with inflation pressure.

\begin{tabular}{lccc}
\hline & $\begin{array}{c}\text { Length } \\
(\mathrm{mm})\end{array}$ & $\begin{array}{c}\text { Diameter } \\
(\mathrm{mm})\end{array}$ & $\begin{array}{c}\text { Inflation } \\
\text { Pressure } \\
(\text { ATM })\end{array}$ \\
\hline $\mathrm{LAD}$ & $29.6 \pm 11.7$ & $2.9 \pm 0.3$ & $14.1 \pm 1.1$ \\
$\mathrm{RCA}$ & $29.3 \pm 13.8$ & $3.0 \pm 0.4$ & $13.7 \pm 1.4$ \\
$\mathrm{LCX}$ & $22.5 \pm 6.6$ & $2.7 \pm 0.3$ & $13.3 \pm 1.2$ \\
\hline
\end{tabular}

Data were presented as Mean \pm SD.

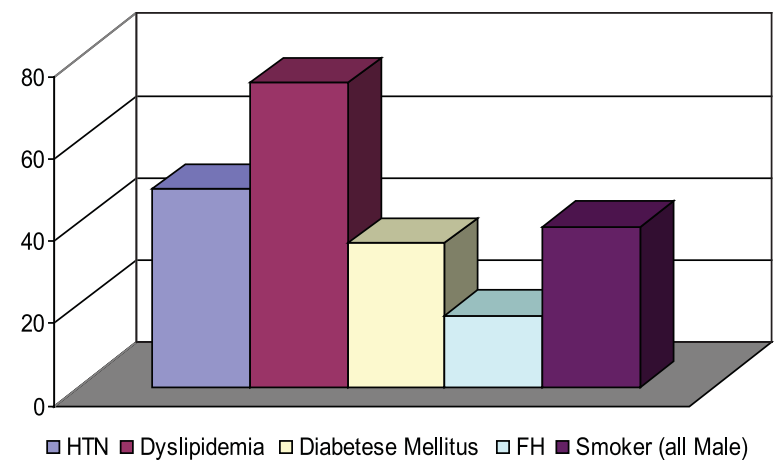

Fig.-1: Percentage distribution of CAD Risk Factors.

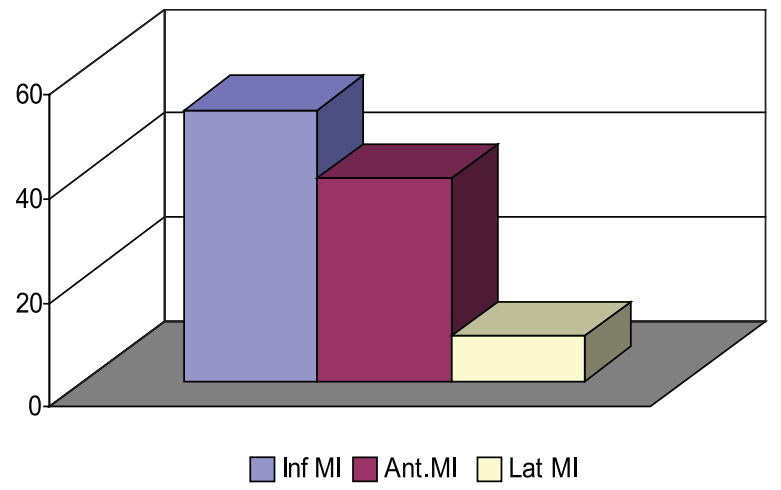

Fig.-2: Percentage distribution of acute STEMI on presentation.

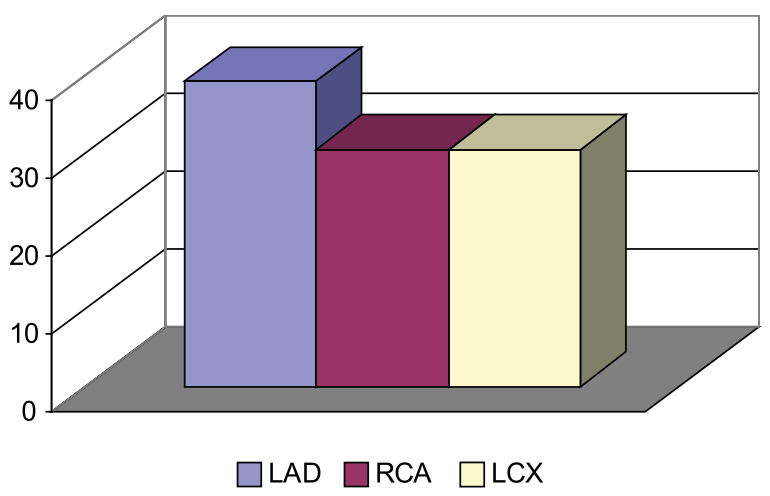

Fig.-3: Percentage distribution of primary PCI of Infarct realted artery. 


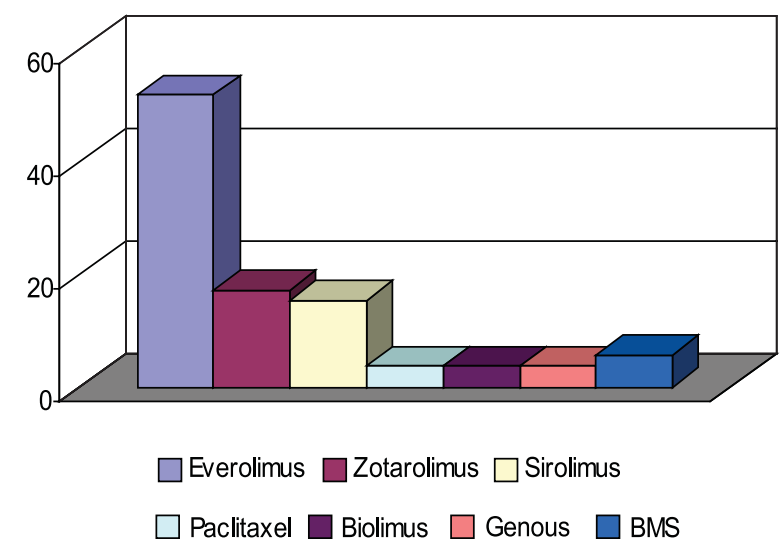

Fig.-4: Percentage Distribution of Different Stent.

Fig 4. Shows the percentage distribution of different DES and bare metal stent (BMS). Among the different DES, Everolimus 26 (52\%), Sirolimus 8(15.4\%) and Zotarolimus 9(17.3\%), Paclitaxel 2 (3.8\%), Biolimus 2 (3.8\%), Genous 2 (3.8\%) was used.

\section{Discussion:}

Patients with acute ST-Segment Elevation myocardial infarction (STEMI) are effectively treated with emergency angioplasty, to restore blood flow to the coronary artery judged to be causing the myocardial infarction, also known as culprit artery. ${ }^{11,12}$ These patients may have major stenosis in coronary arteries that were not responsible for the MI. ${ }^{1}$ Some of the physicians have taken the view that stenosis in non-infarct arteries may cause serious adverse cardiac events that could be avoided by performing PCI during the initial procedures. ${ }^{8,13}$ Others have suggested that medical therapy with antiplatelet, lipid lowering and blood pressure lowering drugs is sufficient and the risk of preventive PCI outweigh the benefit. ${ }^{7,14}$ The meta analysis supports the ACC/AHA guideline advising the performance of primary PCI for STEMI confined to the culprit vessel only. ${ }^{5,15} \mathrm{MV}$-PCI should be discouraged and significant nonculprit vessel lesions should only be treated during planned staged procedures. Although safe, PCI remains associated with potential serious procedural complications, such as restenosis, stent thrombosis, and contrast induced nephropathy. Therefore, international guidelines, recommended using PCI, selectively in cases in which the benefit of a revascularization outweighs the risk complications. It has been hypothesized that for the selected STEMI patients with cardiogenic shock, PCI of the nonculprit vessel in the acute phase is able to reduce (border zone) ischemia and improve survival. ${ }^{16,17}$ In addition when $\geq 1$ culprit lesion is suspected; MV-PCI may also be beneficial. ${ }^{1} \mathrm{MV}$-PCI may also be convenient for the patient, as no second procedures are necessary. Further, there are logistic and economic reasons to perform MV-PCI as it may limit staged procedure, length of hospital stay and medical cost as well.

On the contrary, the possible reason of not to perform MV-PCI in STEMI patient is the enhanced thrombotic and inflammatory environment during acute MI, contributes to a higher risk of procedural complications. ${ }^{18,19}$ Factors that increase the risk in MV-PCI in STEMI patients are related to the complexity and duration of the procedures.

Primary PCI in acute STEMI patients is a primary target of treatment, as it reduces the rate of death and MACE of these acute STEMI patients. Many have MVD, for which the ACC/AHA guide line recommend IRA revascularization, except for the case of haemodynamic instability, which can be managed with multivessel revascularization. ${ }^{3,5}$ Because of the short and long-term mortality of acute STEMI patients with MVDs are higher than those with single vessel disease. ${ }^{2,4}$ It seems that PCI of non-culprit vessel at the time of pPCI would maximize recovery of whole ventricle function by improving myocardial perfusion, thereby producing better clinical outcome. It is known, that vulnerable plaque distribution not limited to IRA in ACS, accounting for the recurrence of angina pectoris, ACS and need for re-PCI of non-IRA. ${ }^{20}$ This supposition is supported by the fact that DES has reduced restenosis and by fact, that the clinical result of MV-PCI have been improved with the availability of technical support of IVUS, FFR and use of a variety of GP IIb/IIIa inhibitors. ${ }^{21-23}$

Very recently, a randomized study called the preventive angioplasty in acute myocardial infarction (PRAMI) trial, was to determine whether performing preventive $\mathrm{PCI}$ as part of the procedure to treat the infarct artery would reduce the combined incidence of death from cardiac causes, nonfatal myocardial infarction or refractory angina. ${ }^{24}$ PRAMI study has demonstrated that 
patients with STEMI and multivessel coronary artery disease undergoing infarct related artery (IRA) PCI, preventive PCI in nonculprit arteries with major stenosis significantly reduced the risk of adverse cardiovascular events, as compared with PCI limited to IRA.

The (Korea acute myocardial infarction registry) KAMIR $^{25}$ investigators did not find any significant differences between IRA revascularization and multivessel revascularization in the rates of 12 month MACE and support the current guidelines that recommend IRA revascularization in haemodynamic stable STEMI patients in the setting of primary PCI. They also suggested that multivessel revascularization might be equally safe and beneficial compared with IRA revascularization done by an experienced interventionist and in the case of multiple culprit lesion if suspected. ${ }^{25}$

In our present era in interventional cardiology, primary PCI is commonly practiced interventional procedure in opening the clogged artery, after having diagnosed as an acute ST-segment elevated myocardial infarction (STEMI). However, a detail on MV-PCI in the same sitting in these patients population with STEMI is not available.

Therefore, we have carried out this very preliminary non-randomized cohort on patient admitting in our hospital with the admission diagnosis of acute STsegment elevated myocardial infarction. In our present study, total 171 acute STEMI patients have primary PCI for the designated period. Total 23 (13.4\%) patient has MVD with STEMI. Primary PCI was done in infarct related artery and the non-culprit vessel in same sitting. Among the studied patients, ECG evidenced admission time diagnosis was inferior wall MI, followed by Anterior and Lateral wall MI. Most commonly stented pPCI territory were; LAD followed by RCA and LCX. Total, 6 (26.1\%) patient has double stent in the infracted territory. DrugEluting stents were more commonly used stents in pPCI. Among the different DES, the mostly used Everolimus eluting stents followed by Sirolimus, Biolimus and Zotarolimus Eluting stents; and Paclitaxel, Genous.

We found that our patients are doing well $>1$-year after the procedure without any MACE, i.e., inhospital mortality, re-infarction, acute or late stent thrombosis. All of our studied patients remain clinically asymptomatic and being regularly followed-up in the cardiac OPD.

Very recently, the PRAMI trial results showed that in patients with acute STEMI, the use of preventive PCI to treat non-infarct coronary artery stenosis immediately after PCI in infarct artery conferred substantial advantages over not performing these additional procedures. The combined rate of cardiac death nonfatal MI or refractory angina was reduced by $65 \%$, an absolute risk reduction of 14 percentage points over 23 months.

Therefore, we recommend doing pPCI in STEMI patients with MVD. To do or not to do pPCI in STEMI patients with MV disease in the same sitting, depends on individual operator expertise and discretion, the disease extent, lesion severity and patient haemodynamic stability and overall the availability of resources. In our current study, number of the patient was very small. Therefore, we were unable to confirm its superiority over staged PCI. In this regards, we need more patient population inclusion; and to do randomized comparative study with "same sitting" and "staged pPCI" in patient with STEMI with a mandatory angiographic follow-up.

\section{Conclusion:}

In the context of our experiences at the Apollo hospitals, we are able to demonstrate the multivessel revascularization of non-culprit lesion during primary PCI of target vessel in the same sitting is safe and uneventful during the procedure and patients remain asymptomatic e" $1 \mathrm{yr}$ after follow without any major adverse cardiac events. Therefore, we recommend for same sitting multivessel PCI, during primary PCI in patients with STEMI and will ensure more myocardial salvage and cost effective for the patient in context of our financial circumstances.

\section{Conflict of Interest - None.}

\section{References:}

1. Goldstein JA, Demetriou D, Grines CL et al. Multiple complex coronary plaque in patients with acute myocardial infarction. N Eng J Med 2000;343:915-922.

2. Sorajja P, Gersh BJ, Cox DA et al. Impact of multivessel disease on reperfusion success and clinical outcomes in 
patients under going primary percutaneous coronary intervention for acute myocardial infarction. Eur Heart J 2007; 28:1709-1716.

3. Muller DW, Topol EJ, Ellis SG et al. Multivessel coronary artery disease: a key predictor of short-term prognosis after reperfusion therapy for acute myocardial infarction (TAMI) study group. Am Heart $J$ 1991;121:1042-1049.

4. Parodi G, Memisha G, Valenti R et al. Five year outcome after primary coronary intervention for acute STsegment elevation myocardial infarction: results from a single center experience. Heart 2005; 91:1541-1544.

5. Kushner FG, Hand M, Smith SC Jr et al. Focused updates: ACC/AHA guidelines for the management of patients with ST-elevation myocardial infarction and ACC/AHA/SCAI guidelines on Percutaneous coronary intervention. A report of the American college of cardiology foundation/American Heart Association Task Force on Practice Guideline. J Am Coll Cardiol 2009;54:2205-2241.

6. Wijns W, Koh P, Danchin N, et al. Guidelines on myocardial revascularization: the Task Force on Myocardial Revascularization of the European Society of Cardiology (ESC) and the European Association for cardio-thoracic surgery (EACTS). Eur Heart J 2010; 31: 2501-2555.

7. Toma M, Buller CE, Westerhout CM et al. Apex-AMI investigators. Non-culprit coronary artery percutaneous coronary intervention during acute ST-segment elevation myocardial infarction: insights from the APEX-AMI trial. Eur Heart J 2010; 31:1701-1707.

8. Politi L, Sgura F, Rossi R et al. Multivessel coronary disease in ST-segment elevation myocardial infarction: three different revascularization strategies and longterm outcomes. Heart 2010; 96:662-667.

9. Kornowski R, Mehran R, Dangas G et al. HORIZONSAMI Trial Investigators $>$ Prognostic impact of staged versus "one-time" multivessel Percutaneous intervention in acute myocardial infarction. $J \mathrm{Am}$ Coll Cardiol 2011; 58:704-711.

10. Di Mario C, Mara S, Flavio A, et al. Single vs multivessel treatment during primary angioplasty: results of multicenter randomized Hepacoat for Culprit or Multivessel stenting for acute Myocardial Infarction (HELP AMI) study. Int J Cardiovasc Intervent 2004; 6:28-33.

11. Kelly EC, Boura JA, Grines $\mathrm{C}$ et al. Primary angioplasty versus intravenous thrombolytic therapy for acute myocardial infarction: a quantitative review of 23 randomized trials. Lancet 2003; 361: 13-20.

12. The task force on the management of ST-segment elevation acute myocardial infarction of the European Society of Cardiology (ESC). ESC guidelines for the management of acute myocardial infarction in patients presenting with ST-segment elevation. Eur Heart $J$ 2012;33:2569-2619.

13. Varani E, Balducelli M, Aquilina M, et al. Single or multivessel PCI in ST-segment myocardial infarction patients. Catheter Cardiovasc Interv 2008; 72:927-933.

14. Hannan EL, Samadashvili Z, Walford G, et al. Culprit vessel PCI versus Multivessel and staged Percutaneous coronary intervention for ST-segment myocardial infarction patients with multivessel disease. JACC Cardiovasc Interv 2010; 3:22-31.

15. Vlaar PJ, Mahmoud KD, Holmes DR, et al. Culprit vessel only versus multivessel and staged Percutaneous coronary intervention for multivessel disease in patient presenting ST-segment elevation myocardial infarction. J Am Coll Cardiol 2011; 58:692-703.

16. Thiele H, Allam B, Chatellier G, Schuler G, Lafont A. Shock in acute myocardial infarction; the Cape Horn for trials? Eur Heart J 2010; 31: 1828-1835.

17. Hochman JS, Sleeper LA, Webb JG, et al. Early revascularization and long-term survival in Cardiogenic shock complicating acute myocardial infarction. JAMA 2006; 295: 2511-2515.

18. Gonzalo N, Barlis P, Serruys PW, Garcia-Garcia HM, Onuma Y, Ligthart $J$ et al. Incomplete stent apposition and delayed tissue coverage are more frequent in drugeluting stents implanted during primary PCI for STsegment elevation myocardial infarction than in drugeluting stents implanted for stable/unstable Angina. $J$ Am Coll Cardiol Interv 2009; 2:445-452.

19. Sianos G, Papafakils MI, Daemen J, Vaina S, van Mieghem CA, van Domburg RT et al. Angiographic stent thrombosis after routine use of drug-eluting stents in ST-segment elevation myocardial infarction: the importance of thrombus burden. $J$ Am Coll Cardiol 2010; 55: 1923-1932.

20. Ambrose JA. In search of the "vulnerable plaque": can it be localized and will focal regional therapy ever be an option for cardiac prevention? J Am Coll Cardiol 2008; 51:1539-1542.

21. Kukreja N, Onuma Y, Garcia-Garcia HM, Daemen J, Domburg R, Serruys PW et al. Three years survival following multivessel PCI with bare-metal or drugeluting stents in unselected patients. Am J Cardiol 2009; 103:203-211.

22. De Luca G, Gibson CM, Bellandi F, Murphy S, Maioli M, Noc M et al. Early glycoprotein IIb/IIIa inhibitors in primary angioplasty (EGYPT) cooperation: an individual patient data meta-analysis. Heart 2008; 94:1548-1558.

23. Tonino PA, De Bruyne B, Pijlis NH, Chase AJ, Edwards RJ, Hughes LO et al. Study investigators, Fractional Flow reserve versus angioplasty for guiding percutaneous coronary intervention. N Eng J Med 2009; 360:213-224.

24. Wald DS, Morris KJ, Wald NJ, Chase AJ, Edwards RJ, Hughes LO et al. Randomized Trial of preventive angioplasty in myocardial infarction. $N$ Eng $J$ Med 369; 12:1115-1123.

25. Lee HW, Hong TJ, Yang MiJ, An SG, Oh JH, Choi JH et al. Comparison of infarct-related artery vs multivessel revascularization in ST-segment elevation myocardial infarction with multivessel disease: analysis from Korea Acute Myocardial Infarction registry (KAMIR). Cardiol J 2012; 19, 3:256-266.

26. Van der Schaaf RJ, Claessen BE, Vis MM, Hoebers LP, Koch KT, Baan J Jr et al. Effect of multivessel coronary disease with or without concurrent chronic total occlusion on one year mortality in patients treated with primary coronary intervention for cardiogenic shock. Am J Cardiol 2010, 105: 955-959. 